www.nature.com/pj

\title{
The preparation of boron-containing aluminoxanes and their application as cocatalysts in the polymerization of olefins
}

\author{
Ryo Tanaka, Takaaki Hirose, Yuushou Nakayama and Takeshi Shiono
}

Boron-moiety-containing aluminoxanes (BMAOs) were prepared from the partial protonolysis of $\mathrm{Me}_{3} \mathrm{Al}$ using various arylboronic acids. Compared with methylaluminoxane (MAO) generated from the hydrolysis of $\mathrm{Me}_{3} \mathrm{Al}, \mathrm{BMAO}$ prepared from $\mathrm{C}_{6} \mathrm{~F}_{5} \mathrm{~B}(\mathrm{OH})_{2}$ and $\mathrm{Me}_{3} \mathrm{Al}$ induced a higher activity at the same Al/Ti ratio in the Ti-based olefin polymerization catalyst (ansa-Me ${ }_{2} \mathrm{Si}(\mathrm{Flu})\left(\mathrm{N}^{\mathrm{t}} \mathrm{Bu}\right)$ $\left.\mathrm{TiMe}_{2} ; 5\right)$. The time course of propylene consumption when using BMAO showed the deactivation of the catalyst, whereas the 5-dMAO system promoted a living polymerization. Among the BMAOs, only those derived from arylboronic acids with electronwithdrawing groups were observed to act as efficient cocatalysts.

Polymer Journal (2016) 48, 67-71; doi:10.1038/pj.2015.81; published online 30 September 2015

\section{INTRODUCTION}

Aluminoxanes are an important class of Lewis acids, frequently used in the activation of olefin polymerization catalysts. The versatile activation properties of methylaluminoxane (MAO), ${ }^{1-3}$ which is the condensation product of $\mathrm{Me}_{3} \mathrm{Al}$ and $\mathrm{H}_{2} \mathrm{O}$, toward transition metal-based coordination-polymerization catalysts have attracted enormous research interest since the discovery of the remarkable potential of $\mathrm{MAO}$ as a cocatalyst in metallocenemediated ethylene polymerization by Kaminsky and Sinn. ${ }^{4}$ However, systematic studies on modifications of MAO remain scarce. This is most likely because MAO usually exists in an equilibrium between linear and cyclic oligomers of varying degrees of polymerization, all of which contain - $\mathrm{Al}(-\mathrm{Me})-\mathrm{O}$ - repeating units. ${ }^{5}$ The elucidation of MAO's precise structure and the mechanistic investigation of polymerizations involving MAO are highly complex, although fragmental information has been gathered over time from nuclear magnetic resonance (NMR), ${ }^{6-12} \mathrm{x}$-ray photoelectron, ${ }^{13}$ infrared (IR) ${ }^{14}$ and ultraviolet-visible, ${ }^{15,16}$ and mass-spectrometry. ${ }^{17}$

Examples of modified MAOs (MMAO) can be categorized into two classes depending on the synthetic route by which they are generated. The first is based on the hydrolysis of alkylaluminum precursors, and the best-known example is probably the commercially available MMAO, which is obtained from the hydrolysis of a mixture of ${ }^{i} \mathrm{Bu}_{3} \mathrm{Al}$ and $\mathrm{Me}_{3} \mathrm{Al} .{ }^{18}$ The limited solubility of MAO in hydrocarbons can be improved by the introduction of branched alkyl groups in the corresponding MMAO precursor. Barron was able to isolate compounds with distorted cage structures, such as $\mathbf{1}$ (Figure 1), from the hydrolysis of ${ }^{t} \mathrm{Bu}_{3} \mathrm{Al} .{ }^{19-23}$ Conversely, the protonolysis of
${ }^{t} \mathrm{Bu}_{3} \mathrm{Al}$ with a bulky arylboronic acid resulted in the formation of a uniform cage structure (2) in very high yield. Compounds 1 and 2 were found to promote $\mathrm{Cp}_{2} \mathrm{ZrMe}_{2}$-mediated ethylene polymerization, although the induced polymerization activity was much lower

than in the presence of an excess of MAO. Eventually, the active species derived from $\mathrm{Cp}_{2} \mathrm{ZrMe}_{2}$ and 1 was identified by ${ }^{1} \mathrm{H}$ NMR analysis as 3 (Figure 1). ${ }^{19-23}$ Recently, the synthesis of an oxo-bridged $\mathrm{Zr} / \mathrm{Al}$ binuclear complex from a mononuclear aluminum complex with a $\beta$-diketimide ligand (4) was reported, and this complex can promote the polymerization of ethylene in the presence of $\mathrm{MAO}^{24}$

The second class of examples of MMAOs is based on the incorporation of elements other than $\mathrm{Al}, \mathrm{O}, \mathrm{C}$ and $\mathrm{H}$ in the aluminoxanes. For example, the introduction of tin into MAO led to an enhanced activation ability, by $20-80 \%$, even though the structure of the resultant compounds could not be precisely determined. ${ }^{25}$ Increased polymerization activities (three to sevenfold) were also observed for modifications of MAO by the reaction with trimethylboroxin $(\mathrm{MeBO})_{3}{ }^{26}$ or $\mathrm{B}\left(\mathrm{C}_{6} \mathrm{~F}_{5}\right)_{3} \cdot{ }^{27}$

These previously reported results prompted us to investigate why the addition of elements other than $\mathrm{Al}, \mathrm{O}, \mathrm{C}$ and $\mathrm{H}$ improved the cocatalyst performance of MAO. For that purpose, we prepared a series of aluminoxanes from $\mathrm{Me}_{3} \mathrm{Al}$ and arylboronic acids with varying electronic parameters. Herein, we describe the synthesis and spectroscopic characterization of aluminoxanes and compare the prepared aluminoxanes' activation properties toward prototypical titanium-based olefin polymerization catalysts. 


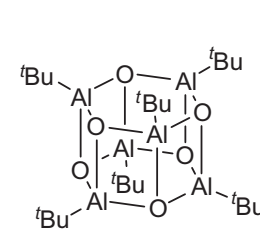

1

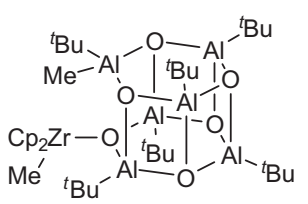

3

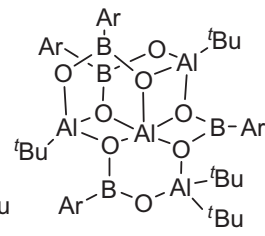

2

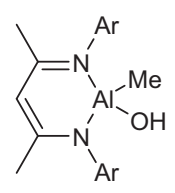

4
Figure 1 Chemical structures of the well-defined aluminoxanes $1-4$.

\section{EXPERIMENTAL PROCEDURE}

\section{General}

All manipulations were performed under a nitrogen atmosphere using standard Schlenk line techniques. MAO was generously donated by Tosoh-Finechem (Yamaguchi, Japan). Dry toluene was purchased from Kanto Chemical (Tokyo, Japan), and traces of residual water were removed by reaction with sodium metal. ansa-Me $\mathrm{Me}_{2} \mathrm{Si}(\mathrm{Flu})\left(\mathrm{N}^{t} \mathrm{Bu}\right) \mathrm{TiMe}_{2}$ (5) and tris(pentafluorophenyl)boroxine were synthesized according to procedures in the literature. ${ }^{28,29}$ Trace amounts of water and $\mathrm{O}_{2}$ were removed from propylene gas (Sumitomo Seika, Osaka, Japan) by passing the gas stream through GC-RP and DC-A4 columns (Nikka Seiko, Tokyo, Japan) prior to use. Other materials were used without further purification. ${ }^{1} \mathrm{H},{ }^{19} \mathrm{~F},{ }^{11} \mathrm{~B}$ and ${ }^{27} \mathrm{Al} \mathrm{NMR}$ spectra were recorded in THF- $d_{8}$ on a Varian 500 NMR spectrometer or LA-500 spectrometer (JEOL, Tokyo, Japan). The obtained ${ }^{1} \mathrm{H}$ NMR spectra were referenced to the signals of the residual traces of the partially protonated solvent $\left(\delta_{\mathrm{H}}(\mathrm{THF})=3.58\right.$ and 1.73 p.p.m. $)$. The calibration was performed using external standards for the other nuclei $\left(\delta_{\mathrm{F}}\right.$ $\left(\mathrm{CFCl}_{3}\right.$ in $\left.\mathrm{CDCl}_{3}\right)=0$ p.p.m.; $\delta_{\mathrm{B}}\left(\mathrm{BF}_{3} \cdot \mathrm{OEt}_{2}\right.$ in $\left.\mathrm{CDCl}_{3}\right)=0$ p.p.m.; $\delta_{\mathrm{Al}}\left(\mathrm{Al}_{(}\left(\mathrm{NO}_{3}\right)_{3}\right.$ in $\left.\mathrm{D}_{2} \mathrm{O}\right)=0$ p.p.m.). The ${ }^{13} \mathrm{C}$ NMR spectrum of the polypropylene was measured using a JEOL-LA-500 spectrometer at $130^{\circ} \mathrm{C}$, using 1,1,2,2-tetrachoroethane- $d_{2}$ as a solvent. The obtained spectrum was referenced to the signals of the residual traces of the partially protonated solvent $(\delta=74.47$ p.p. $\mathrm{m}$.). IR spectra were recorded on a FT/IR-300E spectrometer (JASCO, Tokyo, Japan) using $\mathrm{KBr}$ pellets. The molecular weight of the obtained polymer was determined by GPC on a Viscotec 350B HT-GPC (Viscotec systems, Malvern, UK; $T=150^{\circ} \mathrm{C}$; eluent: $o$-dichlorobenzene) chromatograph calibrated with polystyrene standards. The concentration of polymers in the injecting solutions was ca. $2 \mathrm{mg} \mathrm{ml}^{-1}$, and the injection volume was $0.2 \mathrm{ml}$. Synthetic protocols are identical for all boron-containing aluminoxanes (BMAO1-BMAO7). In the following two sections, representative examples are described in detail for BMAO1.

\section{Preparation of the boron-containing aluminoxane BMAO1}

Pentafluorophenylboronic acid $(211 \mathrm{mg}, 1.0 \mathrm{mmol})$ suspended in toluene $(20 \mathrm{ml})$ was added dropwise to a solution of $\mathrm{Me}_{3} \mathrm{Al}(1.05 \mathrm{mmol}$ in hexane, $0.95 \mathrm{ml}, 1.0 \mathrm{mmol})$ at $0^{\circ} \mathrm{C}$. After the addition was complete, the mixture was heated to $50^{\circ} \mathrm{C}$ and stirred for $12 \mathrm{~h}$. The obtained solution was subsequently used for polymerization experiments without any further purification.

\section{Polymerization of propylene using BMAO1}

Fresh BMAO1 prepared from $\mathrm{Me}_{3} \mathrm{Al}(0.50 \mathrm{mmol})$ and $\mathrm{C}_{6} \mathrm{~F}_{5} \mathrm{~B}(\mathrm{OH})_{2}(0.50$ $\mathrm{mmol}$ ) was suspended in toluene $(29 \mathrm{ml})$. Nitrogen in the headspace of the flask was removed and replaced with propylene at $0{ }^{\circ} \mathrm{C}$ until saturation was achieved. The polymerization was initiated by the addition of $\mathbf{5}(3.7 \mathrm{mg}, 10$ $\mu \mathrm{mol})$ in toluene $(1.0 \mathrm{ml})$ under a steady stream of propylene. After the solution had been stirred for $10 \mathrm{~min}$ at $0{ }^{\circ} \mathrm{C}$, the resultant mixture was poured into $\mathrm{MeOH}(200 \mathrm{ml})$ containing concentrated $\mathrm{HCl}(4 \mathrm{ml})$, and the precipitated
Table 1 Preparation of BMA01-BMA07

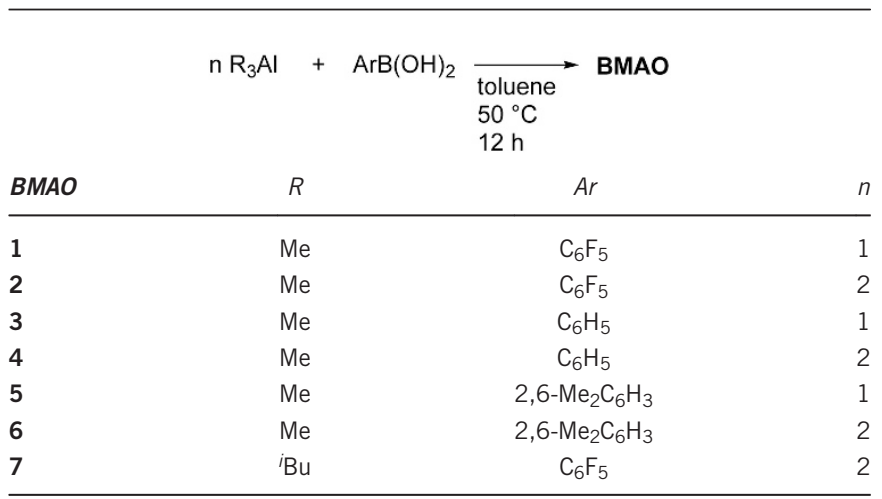

Abbreviation: BMAO, boron-moiety-containing aluminoxane.

polymer was collected by filtration. The obtained polymer was washed with $\mathrm{MeOH}$, and dried for $6 \mathrm{~h}$ at $60^{\circ} \mathrm{C}$ under reduced pressure until a constant weight was measured. Likewise, $963 \mathrm{mg}$ of polypropylene was obtained as a white solid.

\section{RESULTS AND DISCUSSION}

The boron-containing aluminoxanes BMAO1-BMAO7 were prepared by the reaction of trialkylaluminum with arylboronic acids in toluene (Table 1). After incubation for $12 \mathrm{~h}$ at $50^{\circ} \mathrm{C}$, a cloudy solution was obtained. The colorless solids that were obtained after all the volatiles had been removed in vacuo were soluble in THF, partially soluble in benzene and toluene, and insoluble in hexane.

Although these aluminoxanes were complex mixtures, spectroscopic analyses of BMAO1 and BMAO2 were attempted. In the hydride region of the ${ }^{1} \mathrm{H}$ NMR spectrum in THF- $d_{8}$, BMAO1 showed a broad signal at approximately $\delta_{\mathrm{H}}=-1.5$ to 0 p.p.m. with small sharp peaks, whereas BMAO2 showed an additional three sharp peaks, at $\delta_{\mathrm{H}}=-0.65,-0.60$ and -0.35 p.p.m. (Figure 2). According to the assignment of the ${ }^{1} \mathrm{H}$ NMR spectrum of MAO in THF- $d_{8},{ }^{30}$ the broad signal corresponds to the polymeric aluminoxane structure, and the sharp peaks correspond to the mononuclear alkylaluminums. The observed chemical shift of each sharp peak in BMAO2 differed from that of the peak corresponding to $\mathrm{Me}_{3} \mathrm{Al}$ in THF- $d_{8}\left(\delta_{\mathrm{H}}=-1.08\right.$ p.p.m. $)$ but was rather close to that of the peak corresponding to unreacted and unbridged $\mathrm{Me}_{3} \mathrm{Al}\left(\delta_{\mathrm{H}}=-0.53\right.$ p.p.m.), indicating the presence of monomeric alkylaluminum species with a different structure. The integration ratios of the sharp peaks with respect to the broad signal were $1.5 \% \quad\left(\delta_{\mathrm{H}}=-0.65\right.$ p.p.m. $), \quad 1.6 \% \quad\left(\delta_{\mathrm{H}}=-0.60\right.$ p.p.m. $)$ and $1.8 \%$ $\left(\delta_{\mathrm{H}}=-0.35\right.$ p.p.m. $)$, showing that the total content of monomeric alkylaluminum species in BMAO2 was ca. $5 \%$.

The ${ }^{27} \mathrm{Al}$ NMR spectra of BMAO1, BMAO2 and dried MAO (dMAO) each showed a single broad signal at approximately $\delta_{\mathrm{Al}}=60$ p.p.m., for which the chemical shifts were identical to that of aluminoxane (Figure 3). ${ }^{7}$ The half widths of the signals of BMAO1 $\left(\Delta_{1 / 2}=8600 \mathrm{~Hz}\right)$ and BMAO2 $\left(\Delta_{1 / 2}=6800 \mathrm{~Hz}\right)$ were broader than that of dMAO $\left(\Delta_{1 / 2}=3700 \mathrm{~Hz}\right)$, most likely because of the heterogeneity of aluminum in the BMAOs as a result of the incorporation of boron atoms. The peak position of BMAO1 (47.4 p.p.m.) was located at a higher field than for BMAO2 (69.0 p.p.m.) and dMAO (67.0 p.p. $\mathrm{m}$.), indicating that the aluminum center of BMAO1 was more shielded than the aluminum centers of BMAO2 and dMAO. This result implies a stronger coordination of the THF solvent to the aluminum centers in BMAO1 relative to $\mathrm{BMAO} 2$ and $\mathrm{dMAO}$, most 

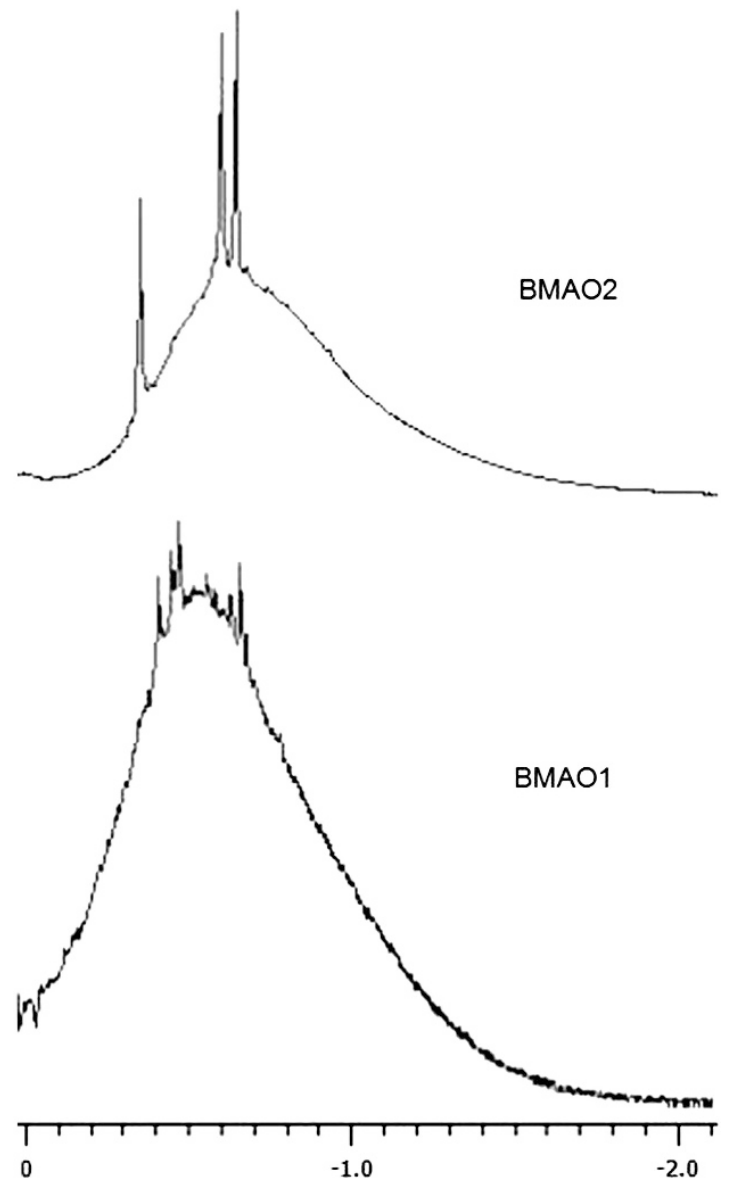

Figure $2{ }^{1} \mathrm{H}$ NMR spectrum of BMAO1 and BMAO2 (500 MHz, THF- $\left.d_{8}\right)$ between -2.0 and 0 p.p.m.

likely because of the stronger Lewis acidity of the BMAO1 aluminum center.

The ${ }^{11} \mathrm{~B}$ and ${ }^{19} \mathrm{~F}$ NMR spectra of BMAO1 and BMAO2 were so complex that precise assignment of the individual signals was impossible see Supplementary Information. However, three broad signals were observed between -110 and -160 p.p.m. in the ${ }^{19} \mathrm{~F} \mathrm{NMR}$ spectra, and several sharp peaks were observed at approximately 525 p.p.m. and $50-60$ p.p.m. in the ${ }^{11} \mathrm{~B}$ NMR spectra, indicating the incorporation of the pentafluorophenyl groups and boron atoms into the polymeric structure. The chemical shift of the former in the ${ }^{11} \mathrm{~B}$ NMR spectra was almost identical to that of $\left(\mathrm{C}_{6} \mathrm{~F}_{5} \mathrm{BO}\right)_{3}$ (boroxin; $\delta_{\mathrm{B}}=18.6$ p.p.m. in $\left.\mathrm{Et}_{2} \mathrm{O}\right),{ }^{31}$ suggesting the presence of a B-O-B moiety. The chemical shift of the latter, on the other hand, was significantly low-field shifted compared with the starting materials, $\mathrm{C}_{6} \mathrm{~F}_{5} \mathrm{~B}(\mathrm{OH})_{2}\left(\delta_{\mathrm{B}}=26.2\right.$ p.p.m. in $\left.\mathrm{Et}_{2} \mathrm{O}\right)$ and boroxin, and was close to the chemical shifts of boric acids, $\mathrm{R}_{2} \mathrm{~B}(\mathrm{OH})$.

In the fingerprint region of the IR spectrum, both BMAO1 and BMAO2 exhibited absorption peaks indicative of O-Al-O asymmetric vibrations $\left(802 \mathrm{~cm}^{-1}\right.$ in BMAO1 and $801 \mathrm{~cm}^{-1}$ in BMAO2 see Supplementary Information), and C-H vibrations at $\sim 2960 \mathrm{~cm}^{-1}$, which was similar to MAO. ${ }^{14}$ Apart from the peaks assigned to aluminoxane, a peak was observed at $1312 \mathrm{~cm}^{-1}$ in BMAO1 and at $1306 \mathrm{~cm}^{-1}$ in BMAO2, and both of these were assigned to the $\mathrm{B}-\mathrm{O}$ bond stretch. The $\mathrm{O}-\mathrm{Al}-\mathrm{O}$ peaks were shifted to lower wavenumbers than those previously reported for MAO $\left(\nu_{\text {asym }}=808 \mathrm{~cm}^{-1}\right)$, thus suggesting longer $\mathrm{O}-\mathrm{Al}$ bonds in BMAO1 and BMAO2.
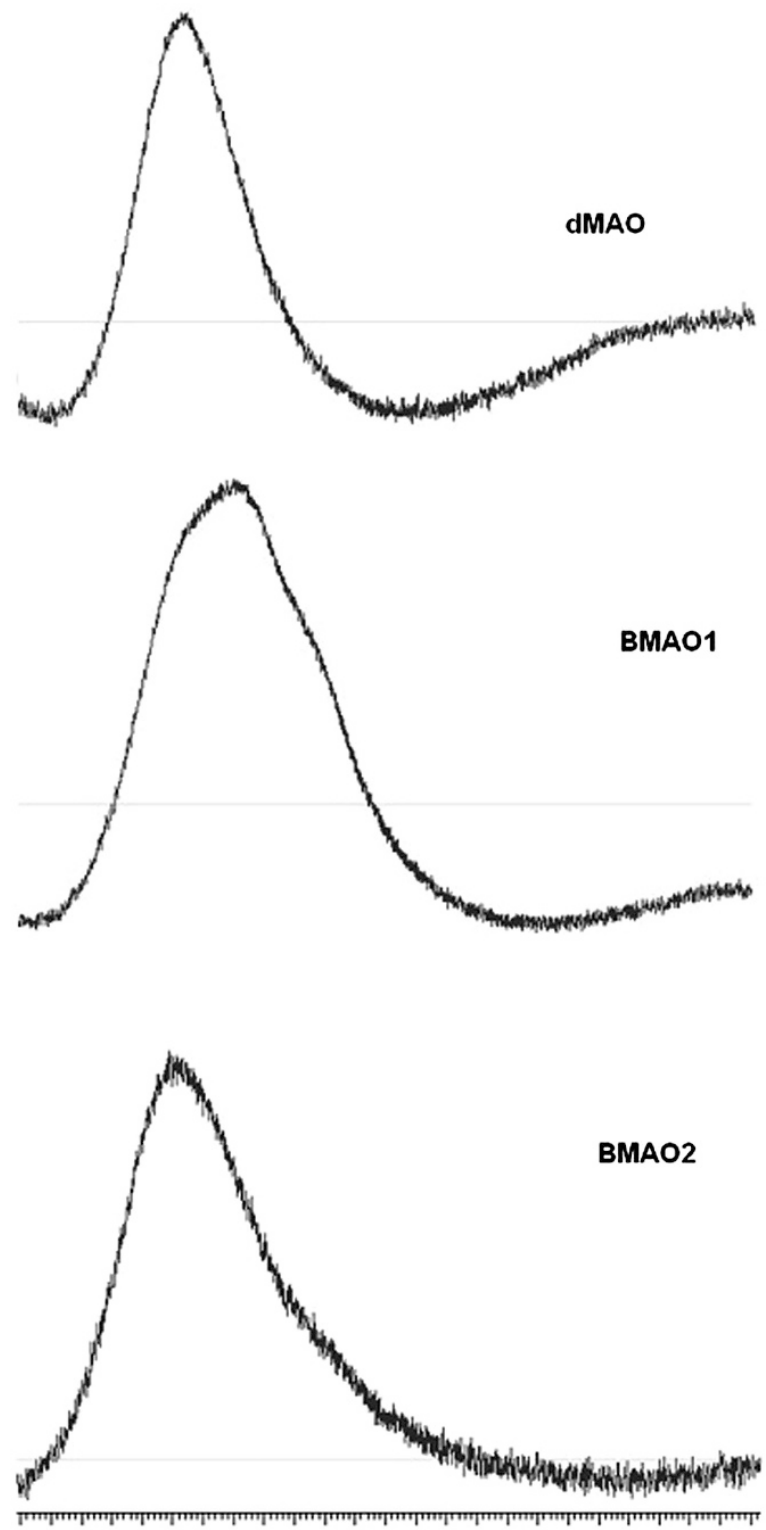

$\begin{array}{llllllllllll}110.0 & 90.0 & 70.0 & 50.0 & 30.0 & 10.0 & -10.0 & -30.0 & -50.0 & -70.0 & -90.0 & -110.0\end{array}$

Figure $3{ }^{27} \mathrm{Al}$ NMR spectrum of BMAO1, BMAO2 and dMAO $(130 \mathrm{MHz}$, $2.0 \mathrm{M}$ in THF- $d_{8}$ ).

Next, we examined the ability of BMAO1-BMAO7 to activate prototypical titanium-based olefin polymerization catalysts (Table 2). Polymerizations were performed at $0{ }^{\circ} \mathrm{C}$ under a propylene pressure of $1 \mathrm{~atm}$ using a titanium complex with a fluorenylamide ligand (5), which promotes a syndiotactic-specific polymerization of propylene. Among the BMAOs examined, only BMAO1 and BMAO2 gave an analyzable amount of polypropylene in the range of an $\mathrm{Al} / \mathrm{Ti}$ ratio of 50-100, whereas BMAO3-BMAO7 did not activate the catalyst. The activities of BMAO1 were higher than those of dMAO and MAO at the same Al/Ti ratio (run 1 vs 7 and 4 vs 9). In order to achieve the same catalyst activity, the amount of dMAO required was 8 times higher than the amount of BMAO1 (run 1 vs 10). The stereotriad distribution of polypropylene obtained using 5-BMAO1 as determined by ${ }^{13} \mathrm{C}$ NMR spectroscopy ( $r r=61 \%$, Figure 4$)$ was almost the same as that obtained using 5-dMAO $(r r=63 \%))^{32}$ The molecular weight of the polymer obtained using BMAO1 was higher than that 


\begin{tabular}{|c|c|c|c|c|c|c|c|c|c|}
\hline Run & $5(\mu \mathrm{mol})$ & $B M A O$ & $A l: B: T i$ & Time (min) & Yield (mg) & $A^{a}$ & $M_{n}^{\mathrm{b}}\left(10^{3}\right)$ & $P D P^{b}$ & $N^{c}(\mu \mathrm{mol})$ \\
\hline 1 & 10 & 1 & 50:50:1 & 10 & 963 & 578 & 748 & 1.8 & 1.3 \\
\hline $4^{d}$ & 20 & 1 & 100:100:1 & 10 & 1884 & 565 & 259 & 1.5 & 7.3 \\
\hline 5 & 20 & 2 & 100:50:1 & 30 & 193 & 19 & 212 & 2.5 & 0.9 \\
\hline 6 & 10 & MAO & $50: 0: 1$ & 30 & Trace & $N D^{e}$ & $N D^{e}$ & $N D^{e}$ & $N D^{e}$ \\
\hline 7 & 10 & dMAO & $50: 0: 1$ & 10 & 68 & 41 & 26 & 10.5 & 2.6 \\
\hline 8 & 20 & MAO & 100:0:1 & 10 & 34 & 10 & 7 & 1.7 & 4.7 \\
\hline 9 & 10 & dMAO & 100:0:1 & 10 & 483 & 290 & 49 & 1.5 & 9.9 \\
\hline
\end{tabular}

Abbreviations: BMAO, boron-moiety-containing aluminoxane; dMAO, dried MAO ; MAO, methylaluminoxane; ND, not determined; PDI, polydispersity index.

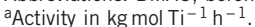

'Determined by GPC calibrated with polystyrene standards.

cNumber of the polymer chain calculated from yield $(\mathrm{g})$ and $M_{\mathrm{n}}\left(\mathrm{g} \mathrm{mol}^{-1}\right)$.

dFurther polymerization cannot be continued because of the ineffective stirring.

eNot determined, as no polymer was obtained.

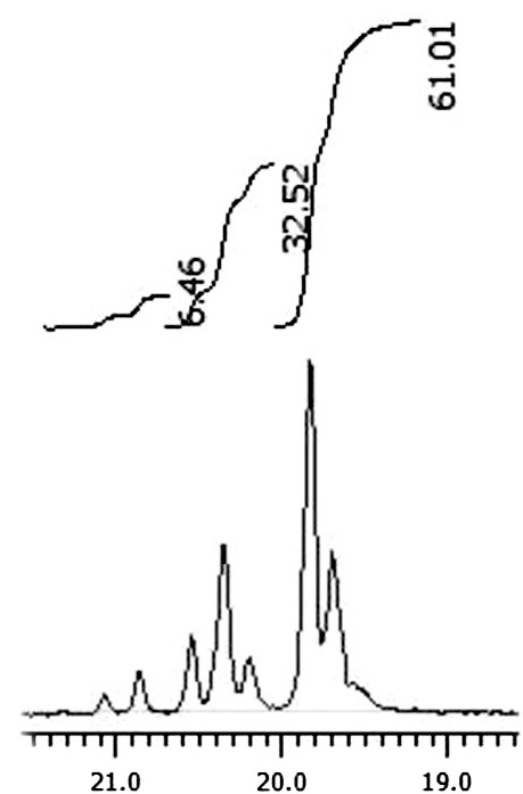

Figure $4{ }^{13} \mathrm{C}$ NMR spectrum of the methyl region of polypropylene obtained from 5-BMAO1 (Table 2, run 1).

obtained using $\mathrm{MMAO}$, indicating that the propagation rate of the 5-BMAO1 system is higher than that of 5-dMAO. This is most likely because of the presence of the $\mathrm{C}_{6} \mathrm{~F}_{5}$ groups, which are electronwithdrawing and should enhance the Lewis acidity of the aluminum center. However, the number of polymer chains obtained using BMAO1 was lower than that obtained using dMAO, indicating that the number of strong Lewis acidic sites in BMAO1 is lower than in dMAO. The polydispersity indexes of the polymers obtained by using BMAO1 were close to 2, and the BMAO1 activity decreased in longer reactions, most likely because of the deactivation of the catalyst (run 1 and 2). The use of $\left(\mathrm{C}_{6} \mathrm{~F}_{5} \mathrm{BO}\right)_{3}$ instead of $\mathrm{C}_{6} \mathrm{~F}_{5} \mathrm{~B}(\mathrm{OH})_{2}$ as the catalyst system resulted in the formation of a trace amount of the polymeric

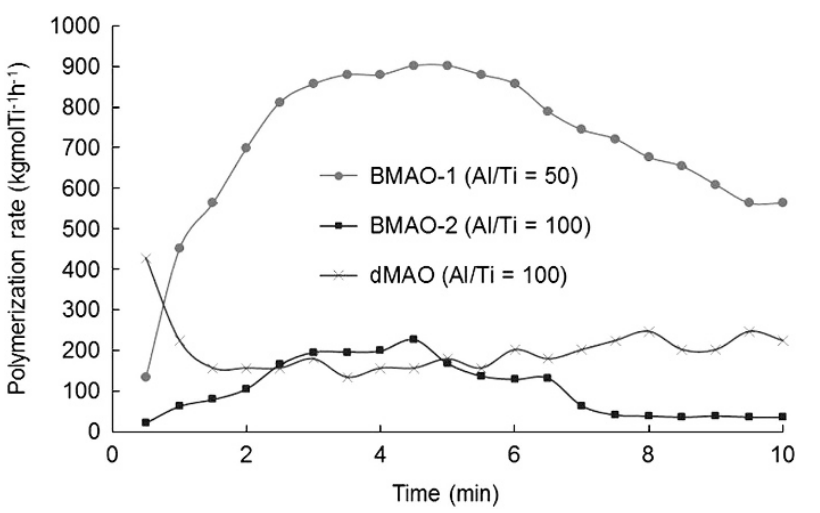

Figure 5 Rate-time profiles of propene polymerization using 5 activated with BMA01, BMAO2 or dMAO (Table 2, Run 1, 5 and 9, respectively).Table 2. Ti-catalyzed polymerization of propylene using BMAOs as cocatalysts.

product, indicating that the protonolysis of $\mathrm{Me}_{3} \mathrm{Al}$ is important in the formation of an active cocatalyst. An increase in the $\mathrm{Al} / \mathrm{Ti}$ ratio increased the number of polymer chains, which is explained by the improvement in the initiation efficiency (run 3 and 4). BMAO2 showed a comparable activity to MAO (run 5 vs 8 ), indicating that the amount of incorporated boron greatly influences the cocatalyst ability. The steric demand of the arylboronic acid was not observed because BMAO3-BMAO6 gave only a trace amount of polymer. BMAO7, which was prepared from ${ }^{i} \mathrm{Bu}_{3} \mathrm{Al}$ and $\mathrm{C}_{6} \mathrm{~F}_{5} \mathrm{~B}(\mathrm{OH})_{2}$, showed no cocatalyst ability. This behavior may arise because the aluminum center is sterically hindered by the isobutyl groups.

Rate-time profiles from the amount of propylene consumed in the 5-BMAO1/BMAO2/dMAO systems are shown in Figure 5. When BMAO1 and BMAO2 were used, the polymerization rate reached a maximum within several minutes and gradually decreased, whereas continuous polymerization proceeded in the 5-dMAO system. Previously, we investigated the effect of the cocatalyst on propylene polymerization by $\mathbf{5}$ and proposed that the counteranion from dMAO 
and $\mathrm{B}\left(\mathrm{C}_{6} \mathrm{~F}_{5}\right)_{3}$ may form less active, but more stable, ion pairs with the active cationic $\mathrm{Ti}$ species and promote a living polymerization. ${ }^{32} \mathrm{On}$ the other hand, non-interacting $\mathrm{Ph}_{3} \mathrm{CB}\left(\mathrm{C}_{6} \mathrm{~F}_{5}\right)_{4}$ resulted in the deactivation of the catalyst, even at $-50{ }^{\circ} \mathrm{C}$. As with $\mathrm{Ph}_{3} \mathrm{CB}\left(\mathrm{C}_{6} \mathrm{~F}_{5}\right)_{4}$, anions from the BMAOs are stable enough and do not interact with the generated Ti cation, thereby resulting in high polymerization rates and a gradual deactivation.

\section{CONCLUSION}

Boron-containing aluminoxanes BMAO1-BMAO7 were prepared from the reaction of $\mathrm{Me}_{3} \mathrm{Al}$ and arylboronic acids. The NMR and IR analyses of the products indicated polymeric structures containing both aluminum and boron atoms. BMAO1 exhibited a higher activation activity toward the Ti-based olefin polymerization catalyst 5 than did MAO or dMAO at the same Al/Ti ratio; this is most likely due to the higher Lewis acidity of the aluminum centers in the Al-O-B structure. These results demonstrate the potential of boronic acids, especially those with electron-withdrawing groups, to act as protonolysis reagents for the preparation of MMAOs, which show desirable activation properties as cocatalysts in olefin polymerizations.

\section{CONFLICT OF INTEREST}

The authors declare no conflict of interest.

\section{ACKNOWLEDGEMENTS}

This work was supported by Grant-in-Aid for Young Scientists (B) (No. 26810070) from the Japan Society for the Promotion of Science (JSPS), Japan. We also greatly appreciate a generous donation of MMAO from TosohFinechem, Japan.

1 Chen, E. Y.-X. \& Marks, T. J. Cocatalyst for metal-catalyzed olefin polymerization: activators, activation processes, and structure-activity relationships. Chem. Rev. 100, 1391-1434 (2000).

2 Pèdeutour, J.-N., Radhakrishnan, K., Cramail, H. \& Deffieux, A. Reactivity of metallocene catalysts for olefin polymerization: influence of activator nature and structure. Macromol. Rapid Commun. 22, 1095-1123 (2001).

3 Zijlstra, H. S. \& Harder, S. Methylalumoxane: history, production, properties, and applications. Eur. J. Inorg. Chem. 2015, 19-43 (2015).

4 Andersen, A., Cordes, H.-G., Herwig, J., Kaminsky, W., Merck, A., Mottweiler, R., Pein, J., Sinn, H. \& Vollmer, H.-J. Halogen-free soluble Ziegler catalysts for the polymerization of ethylene. control of molecular weight by choice of temperature. Angew. Chem. Int. Ed. 15, 630-632 (1976).

5 Gianetti, E., Nicoletti, G. M. \& Mazzocchi, R. Homogeneous Ziegler-Natta catalysis. II. Ethylene polymerization by IVB transition metal complexes/methyl aluminoxane catalyst systems. J. Polym. Sci. Polym. Chem. Ed. 23, 2117-2134 (1985).

6 Sugano, T., Matsubara, K., Fujita, T. \& Takahashi, T. Characterization of alumoxanes by 27Al-NMR spectra. J. Mol. Catal. 82, 93-101 (1993).

7 Babushkin, D. E., Semikolenova, N. V., Panchenko, V. N., Sobolev, A. P., Zakharov, V. A. \& Talsi, E. P. Multinuclear NMR investigation of methylaluminoxane. Macromol. Chem. Phys. 198, 3845-3854 (1997).

8 Bryant, P. L., Harwell, C. R., Mrse, A. A., Emery, E. F., Gan, Z., Caldwell, T., Reyes, A P., Kuhns, P., Hoyt, D. W., Simeral, L. S., Hall, R. W. \& Butler, L. G. Structural Characterization of MAO and Related Aluminum Complexes. 1. Solid-State 27AI NMR with Comparison to EFG Tensors from ab Initio Molecular Orbital Calculations. J. Am. Chem. Soc. 123, 12009-12017 (2001).

9 Babushkin, D. E. \& Brintzinger, H.-H. Activation of dimethyl zirconocene by methylaluminoxane (MAO)-size estimate for Me-MAO anions by pulsed field-gradient NMR. J. Am. Chem. Soc. 124, 12869-12873 (2002).
10 Eilertsen, J. L., Hall, R. W., Simeral, L. S. \& Butler, L. G. Tools and strategies for processing diffusion-ordered 2D NMR spectroscopy (DOSY) of a broad, featureless resonance: an application to methylaluminoxane (MAO). Anal. Bioanal. Chem. $\mathbf{3 7 8}$ 1574-1578 (2004).

11 Sishta, C., Hathorn, R. M. \& Marks, T. J. Group 4 metallocene-alumoxane olefin polymerization catalysts. CPMAS-NMR spectroscopic observation of cation-like zirconocene alkyls. J. Am. Chem. Soc. 114, 1112-1114 (1992).

12 Tritto, I., Li, S., Sacchi, M. C. \& Zannoni, G. IH and 13C NMR spectroscopic study of titanium metallocene-aluminoxane catalysts for olefin polymerizations. Macromolecules 26, 7111-7115 (1993).

13 Gassman, P. G. \& Callstrom, M. R. Isolation, and partial characterization by XPS, of two distinct catalysts in the Ziegler-Natta polymerization of ethylene. J. Am. Chem. Soc. 109, 7875-7876 (1987)

14 Ystenes, M., Eilertsen, J. L., Liu, J., Ott, M., Rytter, E. \& Støvneng, J. A. Experimenta and Theoretical investigations of the structure of methylaluminoxane (MAO) cocatalysts for olefin polymerization. J. Polym. Sci. Part A: Polym. Chem 38, 3106-3127 (2000).

15 Coevoet, D., Cramail, H. \& Deffieux, A. U.V./visible spectroscopic study of the rac-Et (Ind)2ZrCl2/MAO olefin polymerization catalytic system, 1. Investigation in toluene. Macromol. Chem. Phys. 199, 1451-1457 (1998).

16 Coevoet, D., Cramail, H. \& Deffieux, A. U.V./visible spectroscopic study of the rac-Et (Ind)2ZrCl2/MAO olefin polymerization catalytic system, 2. Investigation in $\mathrm{CH} 2 \mathrm{Cl}$. Macromol. Chem. Phys. 199, 1459-1464 (1998).

17 Trefz, T. K., Henderson, M. A., Wang, M. Y., Collins, S. \& Mclndoe, J. S. Mass spectrometric characterization of methylaluminoxane. Organometallics 32 , 3149-3152 (2013).

18 Charpentier, P. A., Zhu, S., Hamielec, A. E. \& Brook, M. A. Effect of aluminoxane on semi-batch polymerization of ethylene using zirconocene dichloride. Polymer 39, 6501-6511 (1998).

19 Mason, M. R., Smith, J. M., Bott, S. G. \& Barron, A. R. Hydrolysis of Tri-tertbutylaluminum: The first structural characterization of alkylalumoxanes [(R2Al)2O]n and (RAIO)n. J. Am. Chem. Soc. 115, 4971-4984 (1993).

20 Harlan, C. J., Mason, M. R. \& Barron, A. R. tert-Butylaluminum hydroxides and oxides: structural relationship between alkylalumoxanes and alumina gels. Organometallics 13 2957-2969 (1994).

21 Harlan, C. J., Bott, S. G. \& Barron, A. R. Three-coordinate aluminum is not a prerequisite for catalytic activity in the zirconocene-alumoxane polymerization of ethylene. J. Am. Chem. Soc. 117, 6465-6474 (1995).

22 Richter, B., Meetsma, A., Hessen, B. \& Teuben, J. H. Synthesis and structural characterisation of a boralumoxane capable of activating a zirconocene ethene polymerisation catalyst. Chem. Commun. 1286-1287 (2001).

23 Richter, B., Meetsma, A., Hessen, B. \& Teuben, J. H. Structural characterization of a cationic zirconocene olefin polymerization catalyst with its methylated boralumoxane counterion. Angew. Chem. Int. Ed. 41, 2166-2169 (2002).

24 Bai, G., Singh, S., Roesky, H. W., Noltemeyer, M. \& Schmidt, H.-G. Mononuclear aluminum hydroxide for the design of well-defined homogeneous catalysts. J. Am. Chem. Soc. 127, 3449-3455 (2005).

25 Kissin, Y. V. \& Brandolini, A. J. An alternative route to methylalumoxane: synthesis, structure, and the use of model methylalumoxanes as cocatalysts for transition metal complexes in polymerization reactions. Macromolecules 36, 18-26 (2003).

26 Fischer, D., Jüngling, S. \& Mülhaupt, R. Donor- and acceptor-modified metallocenebased homogeneous Ziegler-Natta catalysts. Makromol. Chem. Macromol. Symp. 66, 191-202 (1993).

27 Lee, C. H., Lee, S. J., Park, J. W., Kim, K. H., Lee, B. Y. \& Oh, J. S. Preparation of Al (C6F5) 3 and its use for the modification of methylalumoxane. J. Mol. Catal. A 132, 231-239 (1998).

28 Nishii, K., Hagihara, H., Ikeda, T., Akita, M. \& Shiono, T. Stereospecific polymerization of propylene with group 4 ansa-fluorenylamidodimethyl complexes. J. Organomet. Chem. 691, 193-201 (2006).

29 Nair, N. G., Blanco, M., West, W., Weise, F. C., Greenbaum, S. \& Reddy, V. P. Fluorinated boroxin-based anion receptors for lithium ion batteries: fluoride anion binding, Ab initio calculations, and ionic conductivity studies. J. Phys. Chem. A 113, 5918-5926 (2009).

30 Imhoff, D. W., Simeral, L. S., Sangokoya, S. A. \& Peel, J. H. Characterization of methylaluminoxanes and determination of trimethylaluminum using proton NMR. Organometallics 17, 1941-1945 (1998).

31 Frohn, H.-J., Adonin, N. Y., Bardin, V. V. \& Starichenko, V. F. Polyfluoroorganoboronoxygen compounds. 1 polyfluorinated Aryl(dihydroxy)boranes and Tri(aryl)boroxins. Z. Anorg. Allg. Chem. 628, 2827-2833 (2002).

32 Hasan, T., loku, A., Nishii, K., Shiono, T. \& Ikeda, T. Syndiospecific living polymerization of propene with [t-BuNSiMe2Flu]TiMe2 using MAO as cocatalyst. Macromolecules 34, 3142-3145 (2001).

Supplementary Information accompanies the paper on Polymer Journal website (http://www.nature.com/pj) 